\title{
"It was kind of like if it happens it happens. It wasn't planned, it wasn't intentional”: Young mothers' experiences with subsequent pregnancy in Ottawa, Canada
}

\author{
Elyse Fortier $^{a}$ and Angel M. Foster ${ }^{a b *}$

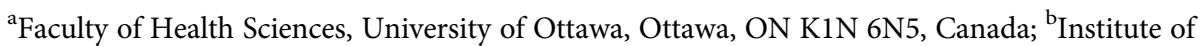 \\ Population Health, University of Ottawa, Ottawa, ON K1N 6N5, Canada \\ *angel.foster@uottawa.ca
}

\section{OPEN ACCESS}

\section{Citation: Fortier E and Foster AM. 2017. "It was kind of like if it happens it happens. It wasn't planned, it wasn't intentional': Young mothers' experiences with subsequent pregnancy in Ottawa, Canada. FACETS 2: 859-87I. doi: I 0.1 I 39/facets-20 I7-0077 \\ Editor: James R. Woodgett}

Received: June 24, 2017

Accepted: August 18, 2017

Published: November 7, 2017

Copyright: (c) 2017 Fortier and Foster. This work is licensed under a Creative Commons Attribution 4.0 International License (CC BY 4.0), which permits unrestricted use, distribution, and reproduction in any medium, provided the original author(s) and source are credited.

Published by: Canadian Science Publishing

\begin{abstract}
Young mothers constitute a vulnerable population in Canada. Teens with children are at significant risk of subsequent pregnancy, a dynamic that can exacerbate health, emotional, and socio-economic challenges. We aimed to understand better the dynamics shaping "rapid repeat pregnancy" among young mothers in Ottawa, explore young mothers' subsequent pregnancy experiences, and identify how services could be improved in Canada's capital. In 2016, we conducted in-depth interviews with 10 young mothers and semi-structured interviews with 10 key informants working with pregnant and parenting youth. We analyzed interviews for content and themes using a multi-phased, iterative process. Four major themes emerged: (1) young mothers often plan their pregnancies actively or passively; (2) violence before, during, and after pregnancy is common; (3) mental health and substance abuse issues shape pregnancy risk; and (4) becoming pregnant often serves as a source of motivation for young mothers. Our results further indicate that young mothers have difficulty finding youthfriendly, non-judgmental support services and that integrated, multidisciplinary services offering individually tailored support and building on women's strengths will likely be more successful in helping young mothers prevent subsequent pregnancies. Increasing awareness about existing services and supporting efforts that approach teen pregnancy comprehensively and holistically appear warranted.
\end{abstract}

Key words: teenage motherhood, adolescent pregnancy, rapid repeat pregnancy, mental health, substance abuse, intimate partner violence

\section{Introduction}

In Canada, it is estimated that every year approximately 40000 adolescent girls become pregnant; roughly 20000 have an abortion and 20000 give birth (Al-Sahab et al. 2012). Young mothers and their children are a vulnerable population requiring support and programmatic attention (Beers and Hollo 2009; Harrison et al. 2014, 2017). Although young mothers can provide children with a loving, stable, and nurturing environment, they often lack a healthy support system, experience high levels of stress, and miss out on important educational opportunities (Luong 2008; Al-Sahab et al. 2012; Kingston et al. 2012). In North America, teenage motherhood is associated with a higher risk of being unemployed or underemployed, living in poverty and in an unhealthy/unsafe environment, having a 
large family and an unstable household, and raising children as a single parent (Singh et al. 2001; Luong 2008; Kingston et al. 2012).

Overarching socio-economic dynamics can impact the health of both young mothers and their children; teen mothers are more likely to develop depression and anxiety than non-parenting teens (Al-Sahab et al. 2012; Hodgkinson et al. 2014; SmithBattle and Freed 2016; Harrison et al. 2017) and the children of teens are at greater risk for educational disabilities and mental health disorders than children born to older parents (Lipman et al. 2011; Kingston et al. 2012). Children of teenage mothers are also $25 \%$ more likely themselves to become adolescent parents, thereby contributing to a complex cycle (Harrison et al. 2017). These educational, socio-economic, and health dynamics can have a negative influence on the development of the mother-child relationship; teenage mothers are more likely than older parents to exhibit difficulty with the task of early parenthood (Singh et al. 2001).

"Rapid repeat pregnancy" is a term used to define the onset of pregnancy within 24 months of a previous pregnancy outcome. This phenomenon is common among youth; approximately $25 \%$ of young mothers will have a second child within two years of the birth of their first child (Luong 2008). Issues already present after the first childbirth often become more serious and difficult to manage after a subsequent delivery. Compared with adolescent mothers with only one child, young mothers with more than one child have lower levels of education, are more likely to live in poverty, and have increased dependence on governmental support (Rotermann 2007; Patchen et al. 2013; Gill et al. 2016). Lack of postpartum contraception (Al-Sahab et al. 2012; Kingston et al. 2012; Pinzon and Jones 2012; Wilson et al. 2013; Whitaker et al. 2016; Sober et al. 2017), experiencing intimate partner violence (IPV), and having mental health and substance abuse issues (Harrison et al. 2014; SmithBattle and Freed 2016) have been identified as key factors associated with multiple pregnancies among youth.

Although some risk factors associated with multiple pregnancies among youth have been identified, there has been a lack of investigation of the experiences of young mothers who have had subsequent or "rapid repeat" pregnancies. In Ontario, the pregnancy rate for women aged 15-19 was 25.7 per 1000 in 2007 (Ontario Ministry of Health and Long-Term Care 2012) and according to the Ottawa Public Health Unit, the teen pregnancy rate decreased from 25 per 1000 teens in 2003 to 18 in 2012 (Ottawa Public Health 2014). However, no information is available about "rapid repeat" pregnancies in either Ontario or Ottawa, and little information is available about the lived experiences of young mothers in these settings. Capturing women's stories is crucial to understanding how services can be improved and (or) expanded. In 2016, we conducted a qualitative study to understand better the experiences of young mothers with subsequent pregnancy and motherhood in Canada's capital.

\section{Methods}

From May to December 2016, we conducted semi-structured in-depth interviews with 10 young mothers and 10 key informants (experts who work with pregnant and parenting youth). To be eligible for the study, young mothers had to be currently residing in Ottawa; be 25 years of age or younger at the time of the interview; have conceived their first child before the age of 20; have had a subsequent pregnancy, irrespective of outcome, within 24 months of the birth of their child; and be sufficiently fluent in English or French to answer interview questions. Using publicly available contact information and personal networks, we recruited key informants who work with teenage mothers in the greater Ottawa area. This group included educators, counsellors, outreach nurses, nurse practitioners, family physicians, and obstetrician-gynecologists. Although we gave participants in both groups the opportunity to engage in telephone, Skype, or in-person interviews, we conducted all interviews over the phone. 


\section{Data collection}

Adopting a community-based recruitment strategy, we posted flyers in the centres that are frequented by young mothers and their children and ads on social media outlets such as Kijiji, Craigslist, and Facebook. Once a young mother expressed interest in the study, we conducted an intake call to ensure eligibility, provide more detailed information about the study, provide the consent form, and schedule an interview time that was convenient for the participant. To recruit key informants, we sent emails detailing the study to experts who had publicly available contact information and to all the major organizations in Ottawa that work with young mothers. After a key informant expressed interest, we sent him/her/them the consent form and scheduled a mutually convenient interview time. At the end of every interview with a key informant, we asked him/her/them to recommend another expert for the study who would have valuable insight on teenage motherhood. Through early participant referral, we were able to recruit experts from various professions allowing us to obtain a range of perspectives.

EF, a master's student in the Interdisciplinary Health Sciences program at uOttawa, conducted all interviews. EF had previous experience working with young mothers and their children and received training from AMF, her supervisor and a medical anthropologist and medical doctor with considerable experience conducting qualitative research on sexual and reproductive health. Using a guide developed specifically for this study, we asked young mothers a series of questions related to their demographic information and reproductive health history, the circumstances and decision-making surrounding their first and subsequent pregnancies, the outcome of all subsequent pregnancies, their experiences with motherhood, and the ways in which services in Ottawa could be expanded or improved. We sent each young mother a \$20 CAD gift certificate to Walmart as a token of our gratitude. In the interviews with key informants, we explored service providers' experiences working with pregnant and parenting youth, the risk factors associated with teenage motherhood and subsequent pregnancy, and their experiences with the different services offered in Ottawa. With the permission of participants in both groups, we audio-recorded and then later transcribed all the interviews, which averaged $60 \mathrm{~min}$ in length.

\section{Data analysis}

During the interviews, EF took detailed notes and she wrote memos shortly thereafter. The memos allowed EF to reflect on the content of the interviews, explore her personal reactions to the information shared, and understand her subjective influence on the interview process (Elo and Kyngäs 2008). The memos also helped the analytic process and allowed us to determine when we reached thematic saturation (Birks et al. 2008); we suspected we had reached thematic saturation after eight interviews with young mothers and completed two additional interviews for confirmation. We analyzed our interviews for content and themes. This was an iterative process that began with data collection and continued with the use of deductive and inductive techniques to develop a codebook (Elo and Kyngäs 2008). We used ATLAS.ti to manage our data, which consisted of transcripts, notes, and memos. After coding our data, we then moved to an iterative phase in which we identified major themes and the relationships between ideas. We analyzed each component of the study separately, and in the final analytic phase we combined results and explored concordant and discordant findings.

\section{Ethical considerations}

The Social Sciences and Humanities Research Ethics Board at the University of Ottawa approved this study (File \#03-16-12). We have used pseudonyms for the young mothers who participated in the study and have masked or redacted all personally identifying information about young mothers and key informants. We have organized our results around significant themes and have also included a 
series of narrative vignettes to provide a thick description (Geertz 1973) of the young mothers who participated in our study.

\section{Results}

\section{Participant characteristics}

The young mothers who participated in our study were between 21 and 25 years of age. Their age when they conceived their first child ranged from 13 to 19 years (inclusive). Participants' level of education varied from having completed grade 10 high school education $(n=2)$ or having a high school diploma $(n=6)$, to being enrolled in a post-secondary education program $(n=2)$. Almost all participants relied on some form of financial assistance such as Ontario Works and all identified as Anglophone and Caucasian. Most participants identified as being a single parent $(n=9)$ and most had experienced living in an unstable situation, including in residences for young mothers $(n=2)$ and shelters $(n=3)$. We provide more information about these participants in Table 1 .

Table 1. Characteristics of the young mothers in our study $(n=10)$.

\section{Characteristic}

\section{Language}

English

French

Race or ethnicity

Caucasian

Relationship status

Single

Long-term partner

Age during study period

21-22

23-24

25

Age when first child was conceived

13-15

16-17

18-19

Number of children during study period

1

2

3

\section{Level of education}

Grade 10 high school
0

10

100

9

1

1 
Table 1. (concluded)

Characteristic

High school diploma

Post-secondary program

Financial assistance ${ }^{a}$

Governmental assistance

Student loans

Family

Subsidized housing

Current living situation

Living on one's own with child/children

Living with a partner

Living in family member's home

Unstable housing/living situation

Ever lived in a residence for young mothers

Ever lived in a shelter

${ }^{a}$ Totals more than $100 \%$ as participants could indicate multiple responses.

The key informants who participated in our study worked in a range of professions and institutions, including all four of the organizations specifically dedicated to young mothers in Ottawa. All key informants had experience as direct service providers, including obstetrician-gynecologists $(n=4)$, prenatal and outreach nurses $(n=2)$, nurse practitioners $(n=1)$, counselors $(n=1)$, and educators $(n=2)$. These experts had over 83 years of combined experience working with young mothers and brought unique perspectives to the issues surrounding teenage motherhood.

\section{Young mothers often plan their pregnancies actively or passively}

Young mothers in our study expressed considerable ambivalence about subsequent pregnancies. Like Kelly (Box 1) most participants did not use any form of contraception after the delivery of their first child. Indeed, six participants explained that although they chose not to use postpartum contraception they were not actively planning on becoming pregnant in the near future. Maureen, a 23-year-old mother of two children, described her feeling toward pregnancy after the birth of her first child as, "It was kind of like if it happens it happens. It wasn't planned, it wasn't intentional". Although a small number of participants expressed a desire to have children close together or to complete childbearing at a young age, most engaged in a more passive strategy that included not using contraception.

Key informants explained that they frequently see young mothers who are actively or passively planning their pregnancies. An obstetrician-gynecologist who works in a centre for pregnant and parenting youth stated that one third of the pregnant adolescents seen at the centre fall into this category. Key informants identified a number of factors influencing the decisions of young mothers including wanting a small age gap between their children, wanting a child of a specific sex, desiring their own family and family stability, and being part of the cycle of teenage motherhood. Although young mothers who participated in our study did not explicitly identify inter-generational cycles of adolescent parenting as a major influence, four participants were born to teenage mothers and nine 
Box 1. Kelly's story.

Kelly, a 23-year-old mother of three, had moved away with her partner at the age of 18 and became pregnant shortly thereafter. After the birth of her twins she experienced significant postpartum depression. She felt overwhelmed with the task of parenthood and felt isolated from her support system. She states that due to her mental health issues and always being at home with her children she did not have time or energy to consider contraception, even though she was not actively trying to become pregnant. She expressed that at the time she was so depressed and unhappy that she had thought to herself that if she became pregnant again it wouldn't make a difference in her life. Two months after the delivery of her twins she found out she was pregnant again. She thought that another child could maybe improve her mental health and decided to continue with the pregnancy. A few months into her second pregnancy, Kelly and her family moved back to Ottawa to be closer to family. Although Kelly loves being a mother, she feels that raising three children without a sufficient support network can be very challenging. At the time of the interview, Kelly was still struggling with mental health issues and stated that she was not accessing any mental health support services. (Interview conducted in November 2016)

described childhood experiences that can be characterized as chaotic. As a family physician who runs a clinic for pregnant and parenting youth explained:

Those that decide to parent you know they've been in a cycle where their mother was a teenager... so they've lived through the experience of that... I remember having one young person, she was 14 and she had planned the pregnancy and I remember having a medical student with me, he was like stunned to hear that she wanted a person to love her for herself and that was her motivation for being pregnant.

\section{Violence before, during, and after pregnancy is common}

Almost all of the young mothers who participated in this study experienced violence and abuse at different stages in their lives. As showcased in Calla's story (Box 2), many expressed having experienced physical, sexual, and (or) emotional violence in their childhoods, in past relationships, and (or) in current relationships. Indeed, nine young mothers reported having experienced IPV prior to and during

Box 2. Calla's story.

Calla is a 23-year-old single mother of two girls. She is enrolled part time in a postgraduate program and also works part time. She lives with her two daughters and recently took in her younger sister's two children. Between the ages of 9 and 13, Calla was sexually abused by her biological brother. At 13, while she was out of town on a school trip, she gave birth to her oldest daughter. At the time she was unaware that she was pregnant and gave birth alone in a bathroom stall. The events that followed were very traumatic: having all of her school friends watch her leave for the hospital on a stretcher with a baby in her arms; disclosing the history of abuse to her family, service providers, and police officers; and having her daughter taken away for the first 6 months of her life due to the nature of the abuse. Once the abuse was known, her biological brother was removed from the family home, subjected to a restraining order, and charged with sexual assault. Calla has since experienced other forms of violence from peers and partners and has experienced various mental health issues. Calla benefitted from counselling until the age of 18. (Interview conducted in August 2016) 
their pregnancies. Twenty-one-year-old Olivia, who obtained an abortion when she became pregnant for the second time, described her experience with the father of her first and only child, "After we had broken up he became very mentally abusive and came back and vandalized my car and physically abused me. I didn't have my daughter in my care at the time; my parents were watching her, thank God". Clare, a 22-year-old mother of two, discussed the abusive relationship she was in when she became pregnant with her second child and explained that she didn't feel safe discussing contraception with her partner. "I don't think I was using birth control at that time. At that point I think that I was in such a difficult place I don't think that even crossed my mind".

A number of young mothers in our study also specifically reported having experienced reproductive coercion perpetrated by a past or current partner. Reproductive coercion refers to a range of behaviours, including contraceptive sabotage, forced abortion or pregnancy, and refusal to engage in safer sex practices that interfere with an individual's ability to make free and autonomous sexual and reproductive health choices (Planned Parenthood Ottawa et al. 2013). Sophie, a 25-year-old mother of three, explained how she became pregnant with her third child a few weeks after giving birth to her second child:

So we had planned a vasectomy and last minute he cancelled his appointment and didn't mention it to me... I had missed my period and I think I was three weeks late. But after that pregnancy I guess because I had breast fed her for 6-7 months so they were never back on schedule yet so I think a month and a half went by before I was like ok [my periods] haven't come back yet what's happening?

Key informants echoed young mothers' experiences and explained that both IPV and reproductive coercion are significant risk factors for "rapid repeat" pregnancy. As an obstetrician-gynecologist working in a specialized centre stated:

$40 \%$ of our young women who are pregnant have experienced violence 6 months prior to pregnancy or during [the] pregnancy. The most common [form of violence] being physical violence by their partner or an ex-partner... screening for violence during pregnancy is extremely important in all pregnancies but especially in teens because it is quite prevalent.

Key informants repeatedly and consistently expressed that integrated, multidisciplinary centres that comprehensively meet the needs of young mothers and provide access to a team of health service providers and social workers are more successful in supporting women who have experienced violence. However, both key informants and young mothers reported that these types of services were lacking in Ottawa.

\section{Mental health issues and substance abuse issues shape pregnancy risk}

Almost all of the young mothers who participated in our study reported having experienced mental health and substance abuse issues. Indeed, nine young mothers recounted histories of anxiety, depression, and postpartum depression and three young mothers, like Jessica (Box 3), described struggling with substance abuse. Susan, a 21-year-old mother of two, explained that she struggled with postpartum depression, which in turn contributed to her alcoholism. "I was clean for a while but like when [my son] came home every other weekend he'd be at [his paternal grandmother's] and every weekend that she didn't have him my mom would have him so I was drunk every weekend". At the time of the interview, Susan reported having been "clean" for 5 months and she had regained full custody of both her children. However, she expressed that it was very challenging for her to find proper mental health support services. "Realistically a lot of young parents need counselling, like there are reasons why we 
Box 3. Jessica's story.

Jessica, a 21-year-old single mother of two, has experienced depression, anxiety, postpartum depression, and multiple forms of violence. She had a difficult childhood that included a history of poverty, unstable housing, and violence. She starting using substances at a young age as a coping mechanism and continued to use drugs and alcohol during all of her pregnancies. As a result of her mental health and substance abuse issues, her partner's mother gained custody of her children for over 6 months. She expresses regret and sadness when thinking about the months she missed with her children and states that her children motivated her to seek help for her mental health and substance abuse issues. When she was attending a centre for young mothers she saw a mental health and addictions counsellor, which was very helpful. However, once she was no longer enrolled at the centre she had to navigate all of the services available in the Ottawa community on her own and few services were available. She put herself on a waiting list and had to wait over 6 months before being assigned a counsellor. When she was finally assigned a counsellor, she did not feel comfortable and had to go back on the waiting list. At the time of the interview she was still waiting to be assigned a new counsellor. (Interview conducted July 2016)

put ourselves into the situations that we are in now, you know? So I feel like counselling ... it takes a while for us to find it". Young mothers in our study repeatedly expressed a need for more youthfriendly mental health services and were generally unaware of the full range of services and programs available in the Ottawa community.

Key informants also identified poor mental health is a significant risk factor for "rapid repeat" pregnancy and believed that young mothers are at heightened risk of a range of disorders when compared with older mothers. An obstetrician-gynecologist explained, "There's a lot of mood disorder that we see during pregnancy and in the postpartum period. Being depressed or being not necessarily mentally healthy in the postpartum can increase the risk of getting pregnant again". Another physician, who works in a specialized centre for young mothers, stated that $30 \%-40 \%$ of the young mothers seen through the centre have underlying mental health issues. However, a number of key informants indicated that available services are currently inadequate.

\section{Becoming pregnant often serves as a source of motivation for young mothers}

Although this study sheds light on negative outcomes associated with teenage motherhood and subsequent pregnancy, many young mothers stated that having children significantly enhanced their lives, as highlighted in Nathalie's story (Box 4). Women repeatedly expressed that having children motivated them to leave an abusive relationship, stop using illicit drugs, alcohol, or tobacco products, and create a better life for themselves. Sonya, a 22 -year-old mother of two, shared how becoming a parent changed her life.

It's probably one of the best decisions I've ever made for myself and really I don't know where I'd be if I hadn't become a mom. I've struggled with like depression my whole life and mental health and stuff like that but being a mom taught me... it's like I saw the unhealthy relationships my parents had and because they were so unhealthy with their relationships and their addictions and not emotionally available and it's like everything they weren't able to do taught me what I needed to make sure I'd be [there] for my son... My sons are a blessing like I really couldn't imagine where I'd be without them. 
Box 4. Nathalie's story.

Nathalie is a 22-year-old single mother of one child. She has shared custody of her son with her ex and although they have parenting disagreements, they are doing their best to co-parent. Nathalie experienced a very difficult childhood where she witnessed unhealthy relationships, mental health and addiction issues, violence, and neglect. Growing up, Nathalie's parents had alcohol and substance abuse problems. When Nathalie was 14 years old she ran away from her biological parents' home. She explains that her biological father had started smoking crack and was getting physically and emotionally abusive with her mother; she ended up being homeless for two years. She ended up getting kicked out of school and she started hanging out with the "wrong people" and using substances. When she was 16 years old she wanted a fresh start and moved to Windsor with her then-partner. However, she was in an abusive relationship and felt very isolated. She became pregnant shortly after and explains that when she found out she was pregnant for the first time she never considered any option other than parenting. She states that the pregnancy forced her to make a better life for herself and to make more mature decisions; soon after she left the abusive relationship and moved back to Ottawa with her mother. She wanted to invest in her future, a process that began with accessing prenatal courses offered by the city of Ottawa. She states that these courses gave her something to look forward to and helped her get excited about the pregnancy. Nathalie states that having her son was the best decision she ever made and that she does not know where she would be without him. She is proud of her parenting skills and of the way she is raising her son despite the various challenges she has faced in the past. (Interview conducted November 2016)

For a number of women in our study, decisions to make life changes were heavily influenced by having contact with the Children's Aid Society (CAS), a government-funded agency created to protect children and youth from abuse and neglect. Indeed, seven of the women in our study had been involved with CAS. Although some described having negative experiences with the agency, several explained how the presence of CAS motivated them to make important changes in their lives and seek additional support or care. As Justine, a 23-year-old mother of two, shared, "[CAS] gave me the option that if I would stay with [my partner] I would never see my daughter again so I chose to leave".

Similarly, key informants expressed that for many young mothers becoming a parent motivated them to pursue their studies, find employment, find stable housing, and provide for their children. A physician who works with young mothers explained, "It's also motivation to finish school and they want to be a good mother and they want to raise their kids not necessarily in the environment that they have been raised. For some it empowers them and they realise they can do something with their life".

Moreover, key informants reported that young mothers who had an especially difficult time raising a first child were often motivated to improve their parenting skills with the second child. Indeed, key informants explained that young mothers who had a negative experience with CAS, such as having their child apprehended, often felt motivated to make important changes in their lives for their future children. As an obstetrician-gynecologist stated,

I've seen at times when some of these women have had children before, when they were in a very, let's say, rough part of their life, and the kids have been taken away by CAS ... but then they sort of figure things out and they get their life on. There's that motivation of it's not going to be like last time, I'm on the straight and narrow here and they are not taking another kid away from me... and they're really motivated. 


\section{Discussion}

Women's experiences with early motherhood and subsequent pregnancy are complex. Their experiences showcase that a range of issues, including violence, mental health disorders, and substance abuse, influence the risk of both initial and subsequent pregnancies. Much effort in recent years has focused on reducing "rapid repeat" pregnancy within this population. Our results suggest that some young mothers are either actively or passively planning subsequent pregnancies. Indeed, consistent with reports from the US, there is significant ambivalence and even fatalism about subsequent pregnancy (Jones et al. 2016). Fatalism is the idea that life events can be predetermined by outside forces such as fate; in the context of unintended pregnancy the concept of "it was meant to be" may facilitate acceptance (Jones et al. 2016). A number of our participants expressed this type of fatalism. Although efforts to promote contraception should continue to be supported, this dynamic must be acknowledged.

Our results echo the findings in the broader literature that suggest there is a need to support efforts to provide integrated, holistic, individualized services. Key informants expressed that providing individualized support to young mothers and helping them to learn parenting skills increases their chances of "success" with their first child, which in turn may reduce young mothers' desire for an immediate subsequent pregnancy. Centres that offer multidisciplinary services and tailored care to young mothers are more likely to be successful in building a young mother's confidence and self-esteem (Pinzon and Jones 2012; Patchen et al. 2013). As illustrated by our findings, many young mothers demonstrate a desire to better their lives when they find out that they are pregnant and decide to parent. Programs that build on this new found motivation are more likely to empower women to continue their education and acquire important skills and find employment (Pinzon and Jones 2012).

Similarly, programs that offer multidisciplinary services on-site appear to be more effective in supporting young mothers who have experienced violence and (or) who have mental health and substance abuse issues. Service providers working in an interdisciplinary team are able to provide more holistic care to young mothers, engage in IPV screening and discussions of reproductive coercion, and assist young mothers in complex processes such as establishing a safety plan in a situation of abuse. However, these processes can take a lot of time, effort, and human resources, which is not always possible in other medical settings. Key informants voiced that most general obstetriciangynecologists and family doctors, that is, those who do not provide obstetric services in tailored settings for pregnant and parenting youth, may be reluctant to inquire about a woman's experience with violence or mental health issues because they do not have or are not aware of the resources available to support that young mother.

There is a significant need to identify non-judgmental, youth-friendly services and programs available in the Ottawa community and to make service providers and young mothers aware of them. Raising awareness and creating community ties will provide support to service providers and allow them to appropriately refer young mothers. Creating strategies to making these services visible appears warranted. This can be accompanied by outreach efforts to ensure that young mothers in need are able to access multidisciplinary centres and programs.

All of the young mothers that were interviewed were white and Anglophone. Therefore, perspectives of women from different ethnic groups and language-minority communities are not reflected in our data. Future research would benefit from inclusion of these voices. Also, young mothers with more stable lives and partners are less likely to participate in this type of study or need services through area organizations. Their voices are also not included in this research. This study focused on greater Ottawa, which limits the transferability of results. For future studies, this limitation could be taken into account and the scope of the study widened to include a sample from across the province or throughout 
Canada. Finally, the temporal nature of the study is such that policy changes influencing sexual and reproductive health services in Ontario that occurred after 2016 would not be reflected in our data.

Despite these limitations, our findings give voice to the experiences of young mothers in Ottawa. Although every young mother's experience is unique, the intersection between subsequent pregnancy, violence, mental health issues, and substance abuse appears common. Supporting and further developing non-judgmental, youth-friendly, holistic services appears warranted.

\section{Acknowledgements}

Dr. Foster's 2011-2016 Endowed Chair in Women's Health Research was funded by the Ministry of Health and Long-Term Care in Ontario and we appreciate the general support for her time that made this project possible. We are also grateful to the Society of Family Planning for a mentorship grant that supported this work. The conclusions and opinions expressed in this paper are those of the authors and do not necessarily represent the views of the organizations with which the authors are affiliated or the funders.

\section{Author contributions}

$\mathrm{EF}$ and AMF conceived and designed the study. EF performed the experiments/collected the data. EF and AMF analyzed and interpreted the data. EF and AMF contributed resources. EF and AMF drafted or revised the manuscript.

\section{Competing interests}

The authors have declared that no competing interests exist.

\section{Data accessibility statement}

All relevant data are within the paper.

\section{References}

Al-Sahab B, Heifetz M, Tamim H, Bohr Y, and Connolly J. 2012. Prevalence and characteristics of teen motherhood in Canada. Maternal and Child Health Journal, 16(1): 228-234. PMID: 21298506 DOI: $10.1007 / \mathrm{s} 10995-011-0750-8$

Beers LAS, and Hollo RE. 2009. Approaching the adolescent-headed family: a review of teen parenting. Current Problems in Pediatric Adolescent Health Care, 39(9): 216-233. PMID: 19857857 DOI: $10.1016 /$ j.cppeds.2009.09.001

Birks M, Chapman T, and Francis K. 2008. Memoing in qualitative research: probing data and process. Journal of Research in Nursing, 13(1): 68-75. DOI: 10.1177/1744987107081254

Elo S, and Kyngäs H. 2008. The qualitative content analysis process. Journal of Advanced Nursing, 62(1): 107-115. PMID: 18352969 DOI: 10.1111/j.1365-2648.2007.04569.x

Geertz C. 1973. The interpretation of cultures: selected essays by Clifford Geertz. Basic Books, New York, New York.

Gill R, Black A, Dumont T, and Fleming N. 2016. Photovoice: a strategy to better understand the reproductive and sexual health needs of young mothers. Journal of Pediatric \& Adolescent Gynecology, 29(5): 467-475. PMID: 26992608 DOI: 10.1016/j.jpag.2016.03.001 
Harrison ME, Weinstangel H, Dalziel N, and Moreau KA. 2014. A collaborative outreach clinic for pregnant youth and adolescent mothers: description of a pilot clinic and its patients. Paediatrics \& Child Health, 19(5): 247-250. PMID: 24855427 DOI: 10.1093/pch/19.5.247

Harrison ME, Clarkin C, Rohde K, Worth K, and Fleming N. 2017. Treat me but don't judge me: a qualitative examination of health care experiences of pregnant and parenting youth. Journal of Pediatric \& Adolescent Gynecology, 30(2): 209-214. PMID: 27742428 DOI: 10.1016/j.jpag.2016.10.001

Hodgkinson S, Beers L, Southammakosane C, and Lewin A. 2014. Addressing the mental health needs of pregnant and parenting adolescents. Pediatrics, 133(1): 114-122. PMID: 24298010 DOI: $10.1542 /$ peds.2013-0927

Jones RK, Frohwirth LF, and Blades NM. 2016. "If I know I am on the pill and I get pregnant, it's an act of God": women's views on fatalism, agency and pregnancy. Contraception, 93(6): 551-555. PMID: 26872719 DOI: 10.1016/j.contraception.2016.02.005

Kingston D, Heaman M, Fell D, and Chalmers B. 2012. Comparison of adolescent, young adult, and adult women's maternity experiences and practices. Pediatrics, 129(5): e1228-e1237. PMID: 22529278 DOI: 10.1542/peds.2011-1447

Lipman EL, Georgiades K, and Boyle MH. 2011. Young adult outcomes of children born to teen mothers: effects of being born during their teen or later years. Journal of the American Academy of Child \& Adolescent Psychiatry, 50(3): 232-241.e4. PMID: 21334563 DOI: 10.1016/j.jaac.2010.12.007

Luong M. 2008. Perspectives on labour and income: life after teenage motherhood. Catalogue no. 75-001-X. Statistics Canada, Ottawa, Ontario [online]: Available from statcan.gc.ca/pub/ 75-001-x/2008105/article/10577-eng.htm.

Ontario Ministry of Health and Long-Term Care. 2012. Initial report on public health: teen pregnancy [online]: Available from health.gov.on.ca/en/public/publications/pubhealth/init_report/tp.html.

Ottawa Public Health. 2014. State of Ottawa's Health, 2014 [online]: Available from documents. ottawa.ca/sites/documents.ottawa.ca/files/documents/stateOfHealth2014_en.pdf.

Patchen L, LeTourneau K, and Berggren E. 2013. Evaluation of an integrated services program to prevent subsequent pregnancy and birth among urban teen mothers. Social Work in Health Care, 52(7): 642-655. PMID: 23947540 DOI: 10.1080/00981389.2013.797538

Pinzon JL, and Jones VF. 2012. Care of adolescent parents and their children. Pediatrics, 130(6): e1743-e1756. PMID: 23184113 DOI: 10.1542/peds.2012-2879

Planned Parenthood Ottawa, Ottawa Coalition to End Violence Against Women, Canadians for Choice, and Canadian Federation for Sexual Health. 2013. Bridging services for women: coordinating a community response to violence against women and sexual and reproductive health. Planned Parenthood Ottawa, Ottawa, Ontario.

Rotermann M. 2007. Second or subsequent births to teenagers. Catalogue no. 82-003. Statistics Canada, Ottawa, Ontario [online]: Available from statcan.gc.ca/pub/82-003-x/2006002/article/ mothers-meres/9525-eng.pdf.

Singh S, Darroch JE, and Frost JJ. 2001. Socioeconomic disadvantage and adolescent women's sexual and reproductive behavior: the case of five developed countries. Family Planning Perspectives, 33(6): 251-258, 289. PMID: 11804434 DOI: 10.2307/3030192 
SmithBattle L, and Freed P. 2016. Teen mothers' mental health. MCN, The American Journal of Maternal/Child Nursing, 41(1): 31-36. PMID: 26474475 DOI: 10.1097/NMC.0000000000000198

Sober S, Shea JA, Shaber AG, Wittaker PG, and Schreiber CA. 2017. Postpartum adolescents' contraceptive counselling preferences. The European Journal of Contraception \& Reproductive Health Care, 22(2): 83-87. PMID: 28058853 DOI: 10.1080/13625187.2016.1269161

Whitaker R, Hendry M, Aslam R, Booth A, Carter B, Charles JM, et al. 2016. Intervention Now to Eliminate Repeat Unintended Pregnancy in Teenagers (INTERUPT): a systematic review of intervention effectiveness and cost-effectiveness, and qualitative and realist synthesis of implementation factors and user engagement. Health Technology Assessment, 20(16): 1-214. PMID: 26931051 DOI: $10.3310 /$ hta20160

Wilson EK, Fowler CI, and Koo HP. 2013. Postpartum contraceptive use among adolescent mothers in seven states. Journal of Adolescent Health, 52(3): 278-283. PMID: 23299019 DOI: 10.1016/j. jadohealth.2012.05.004 